\title{
Captagon, Octodrine, and NBOMe: An Integrative Analysis of Trends Databases, the Deep Web, and the Darknet
}

\author{
Ahmed Al-Imam ${ }^{1,2}$ \& Ban A. AbdulMajeed ${ }^{3}$ \\ ${ }^{1}$ Department of Postgraduate Medicine, School of Life and Medical Sciences, University of Hertfordshire, United \\ Kingdom \\ ${ }^{2}$ Department of Anatomy and Cellular Biology, College of Medicine, University of Baghdad, Iraq \\ ${ }^{3}$ Department of Pathology and Forensic Medicine, College of Medicine, Al-Nahrain University, Iraq \\ Correspondence: Dr Ahmed Al-Imam, House 18/5, Al-Akhtal Street, District 318, Al-Adhamyia, 10053, Baghdad, \\ Iraq. E-mail: tesla1452@gmail.com; a.m.al-imam@herts.ac.uk
}

Received: July 25, 2017 Accepted: August 17, 2017 Online Published: September 18, 2017

doi:10.5539/gjhs.v9n11p114

URL: https://doi.org/10.5539/gjhs.v9n11p114

\begin{abstract}
Background: Captagon, Octodrine, and NBOMe are unique substances; each represents a chemical category of its own pharmacodynamic and pharmacokinetic properties. Captagon is an amphetamine-type stimulant, while octodrine is a sympathomimetic agent, on the other hand, NBOMe is a hallucinogen (psychedelic substance). However, the mechanism of action for each is exerted via monoamine transporters.

Materials and Methods: This study will explore these substances using an integrative approach via the analysis of the surface and deep web, and a trends database. The aims are; to visualise the extent of diffusion of each substance on the internet, conclude the geo-mapping for the diffusion, to see if the patterns are compatible on both divisions of the web, and to infer data on the basis of the power (authority) for e-vendors on the darknet e-marketplace. This study is a hybrid of cross-sectional and retrospective analyses.

Results: Google Trends analyses confirmed that the popularity of captagon is ahead over both NBOMe and octodrine; captagon popularity was correlated with terror attacks in the developed world, particularly in western European countries. The contribution of the developing countries to the diffusion of these substances, including the Middle East, was minimal.

Conclusion: This study proposes a novel method to analyse the e-markets on the darknet via the use of; analysis of the basis of power, inferential statistics, geo-mapping in parallel with data from Google Trends database. Data from Google Trends can serve as a foundation for data mining techniques for an efficient warning system against an anticipated swarm of intoxications or an attack of terror.
\end{abstract}

Keywords: Novel Psychoactive Substance, NPS, Captagon, Octodrine, Nbome, Fenethylline, Dmha, 2-Aminoisoheptane, Surface Web, Deep Web, Darknet, Google Trends, geographic mapping, power (psychology), medical informatics

\section{Background}

The situation on novel psychoactive substances (NPS) has been escalating to an unprecedented level; the diffusion and abundance of these substances poses an economic, public, health, and terror threats on a global scale (Al-Imam et al., 2017; Krabseth et al., 2016; Orsolini et al., 2016). In this study, three distinct substances will be explored; Captagon (fenethylline), Octodrine (DMHA), and n-bomb (NBOMe). Each of these substances represents a unique class of its own and having its peculiar pharmacodynamics and pharmacokinetics; captagon is an amphetamine-type stimulant (ATS), octodrine is a sympathomimetic agent, while NBOMe is a hallucinogenic substance (psychedelic) (Ling et al., 2013; Nichols 2016; Rao and Hoffman, 2014). The final common pathway shared by the three substances is the central monoamines (dopamine, serotonin, and catecholamines), and to a lesser extent peripheral monoamines (in case of octodrine); their main action is exerted via the monoamine transporters (MAT) (Mayer et al., 2016; Simmler et al., 2014).

Captagon has been linked to the terror attacks in Western Europe in the past years; it is an amphetamine-type stimulant which can highly potentiate the physical abilities of its users by reducing the need for rest and sleep. Hence, it has been widely used in conflict zones by militias and terrorist organizations, and in the planning for 
terror attacks (Al-Imam et al., 2016; Al-Imam et al., 2017; Kravitz et al., 2016). On the other hand, NBOMe is a hallucinogenic substance and an entheogen, which can be used to reach an "advanced" spiritual and cognitive states (Al-Imam, 2017; Dos Santos et al., 2016). There are several variants of it; the most popular are the 25c, 25b, and $25 \mathrm{i}$ (Kyriakou et al., 2015). The 25i variant is the most potent even in microgram doses, which put NBOMe on the list of most fatal hallucinogens (Chung et al., 2016; Shanks et al., 2014). Octodrine appears to be a much simpler drug, long forgotten after its discovery, it has re-emerged as a physiological-psychological stimulant due to its sympathomimetic properties; it is now used for pre-workout regiments by athletes and allied users (Charlier, 1951; Fellows, 1947). To date, there are no human experimentations, and very few animal studies on each of octodrine and NBOMe; their pharmacodynamic and pharmacokinetic properties are far from being understood.

This study will explore each substance in an integrative and comparative approach, via the analysis of surface and deep web, and a trends database. The aims are; to visualise the extent of substances diffusion on the internet, to perform geo-mapping in connection with the dissemination, to see if surface and deep web patterns (trends) are compatible, and to infer data on the basis of the power for e-vendors who are dealing with these substances on the darknet e-marketplace. The analysis will be based on cross-sectional (internet snapshots) and longitudinal analysis (retrospective); these are merely iconic studies. Hence, data mining may offer a solution which has never been implemented before in connection with the discipline of NPS. Data mining will provide an impressive real-time output of data on the diffusion of substances and the changes in the trends (Fayyad et al., 1996; Han et al., 2011).

\section{Materials and Methods}

Three chemical substances; captagon (fenethylline), octodrine (DMHA), and nbome (n-bomb) were analysed in relation to their popularity, trends, geo-mapping, and e-commerce. The analyses were carried out based on data retrieved from a trends database (Google Trends), surface web, and the deep web and its darknet e-marketplace; specific attention was directed towards the AlphaBay e-market (Celestini et al., 2017). The analyses were comparative for the three substances, these were followed by an in-depth analysis of each substance.

The implemented inferential statistical tests included Student's t-test (independent and paired), ANOVA (single factor), and linear correlation (regression model). The significance of results was considered and an alpha value of 0.05 and a confidence interval (CI) of $95 \%(95 \% \mathrm{CI})$. The initial (inceptive) analysis was carried out based on data retrieved from Google Trends database; the aim was to reach an inference by comparing the popularity of these substances among users of the surface web. Data from Google Trends were analysed for the period from the beginning of 2012 to the end of 2016 (retrospective, longitudinal analysis). Interpretation of the trends database was based on the use of a keyword pair for each substance, made of a generic name and chemical name; octodrine (DMHA), captagon (fenethylline), and n-bomb (NBOMe).

The examination of the deep web was carried out via the Tor browser and Grams search engine (Buxton and Bingham, 2002; Biddle et al., 2015; Mulazzani et al., 2013). Captagon was examined (internet snapshot, cross-sectional analysis) on the e-markets of the darknet; data were retrieved regarding the advertised quantities, e-markets, e-vendors, shipping countries, the number of e-vendors per country, and the power scoring for e-vendors. The e-vendor's power (authority) was calculated based on the level of e-vendor, the number of positive feedbacks (by e-customers), and the number of negative feedbacks. The shipping countries were also examined for the contribution of the Middle Eastern and Arabic countries. In relation to nbome, data were more abundant on the darkest e-markets; the analyses were carried out in connection with three renowned e-markets; AlphaBay, HANSA, and Valhalla. Given the abundance of data, a more in-depth inferential conclusion was feasible. Retrieved data included the type of advertised nbome, its e-market, e-vendors' characteristics, and regional e-commerce data (shipping countries). A power score was calculated and assigned for each e-vendor; scoring was based on the e-vendor characteristics including; vendor level, trust level, the number of positive and negative feedback, the number of advertised items, the number of subscribers, and the duration of membership for e-vendors within each e-market. Power score calculation was reliable to be later correlated with the extrapolated data on geo-mapping; the contribution of the Middle East was also conveyed eventually.

\section{Results and Discussion}

Based on Google Trends analyses, users of the surface web were more interested in captagon than in either nbome or octodrine (Figure 1). Users were aware of both the generic name and the chemical name of captagon. On the other hand, the use of the chemical name was more familiar than the generic name for nbome. Both names, generic and chemical, of octodrine were poorly known. The popularity in ascending order; octodrine (dmha), nbome (n-bomb), and captagon (fenethylline). 


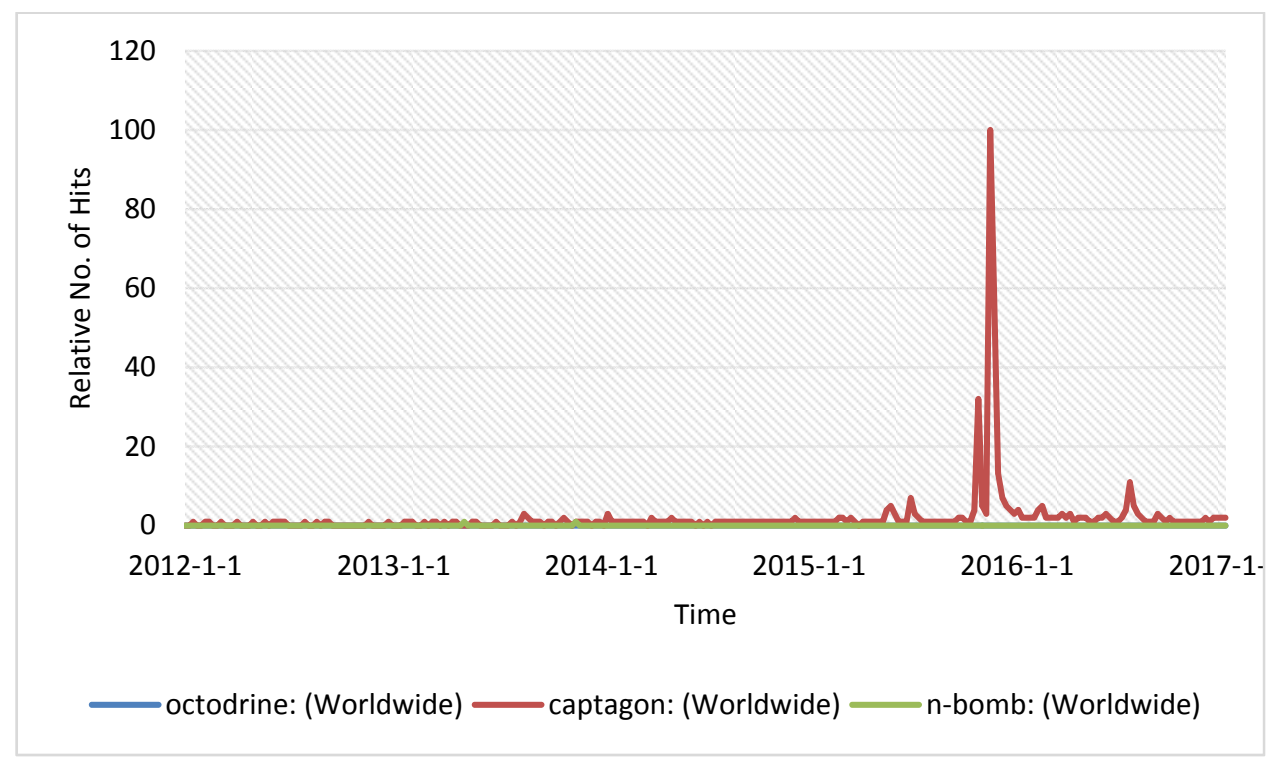

Figure 1. Google Trends (2012-2016): Octodrine, Captagon, and NBOMe

Retrospective analysis shows a steady trend for octodrine over a duration of five years (2012-2016), an almost steady trend for nbome, and unstable (changeable) trend for captagon. The popularity for nbome increased in an episodic fashion by up to $200-250 \%$ over the baseline at specific dates; June (2013), July (2013), August (2013), October (2014), May (2015), June (2016). On the other hand, captagon was steady over the years (2012-2016) except in late 2015 in October and November (highest peak), and the middle of 2016 (July). There was also a relatively small rise in the trends in June (2015) with reference to both the generic name (captagon) and the chemical name (fenethylline). Most of these increments were sudden and in correlation with terror attacks particularly in Europe (Al-Imam et al., 2017). It is very evident that trends databases, including Google Trends, can give a clear insight and should be integrated into early warning systems in anticipation of a terror attack or incidents of intoxications and fatalities induced by these substances. The highest rise in captagon trends was exactly around the middle of November (2015) to the $1^{\text {st }}$ week of December (2015), the increment in the trends peaked at 100x above the baseline, which is an obvious statistical outlier; it coexisted in correlation with the terror attacks. The potentials of data mining exist here to anticipate and prevent attacks of terrorism; data mining relies on databases to be analysed using inferential models of data science with some degree of automation (artificial intelligence); the reward from such application will be remarkable to enhance security, preserve human lives, and reduce the burden of the collateral economic induced by these substances (Kohavi \& Provost, 2001).

Though it was apparent that captagon was taking the lead all over the years, particularly in 2015 and 2016, inferential statistics were essential to be executed. The Analysis of Variance (single factor, ANOVA) confirmed the existence of statistically discernable trends $(p$-value $<0.001)$ among the three substances. The unpaired Student's $t$-test has shown that captagon is taking the lead ahead of both octodrine $(\mathrm{p}<0.001)$ and nbome $(\mathrm{p}<0.001)$. On the other hand, there was no significant difference between nbome and octodrine $(\mathrm{p}=0.079)$ at $95 \%$ CI. Retrospective inference (2012-2016) indicated that there was no significant change in the individual trends for each substance, neither for octodrine nor for nbome. However, change of captagon trends over time revealed a steady trend over the years with an exception for; 2012 versus 2015 ( $p=0.009), 2013$ versus 2015 ( $p=0.013), 2014$ versus 2015 $(\mathrm{p}=0.019)$, and to a less extent for 2015 versus $2016(\mathrm{p}=0.059)$, the latter is significant at $90 \%$ CI. It is to be concluded that the attentiveness of surface web users towards captagon has significantly increased in 2015 .

Regional interest (geo-mapping of trends) in relation to captagon shows that the top countries were; France (34\%), Turkey and Germany (each at 15\%), Italy (11\%), Canada and Spain (each at 10\%), and the US (5\%). Using the chemical name (fenethylline) to retrieve the geo-map of the trends (Figure 2) showed a comparable pattern; the top contributing countries with an interest in fenethylline were; France (35\%), Germany (15\%), Turkey (15\%), Canada $(10 \%)$, Spain $(10 \%)$, Italy $(10 \%)$, and the US (5\%); there was also a minor contribution from Australia, Russia, Brazil, and the UK. It is to be concluded that attentiveness of surface web users towards both keywords for captagon, generic and chemical, is well established. However, this is not the case for octodrine and nbome, in which the generic name is more familiar than the chemical name. Geomapping of nbome trends revealed five leading countries of interest; US (30\%), Australia (27\%), Russia (18\%), Brazil (15\%), and the UK (10\%). It seems 
that the pattern is differentiated from that of captagon. Captagon is popular in western European countries and North America, while nbome appears to be popular in the US, Asia, Australia, Latin America, and England. Furthermore, Middle Eastern and Arabic countries did not contribute by any means to the geo-map of the trends. The e-trade of these substances seems to be of a high affinity in relation to western countries, and more of an issue for the developed countries with the exception of Brazil and in connection with nbome.

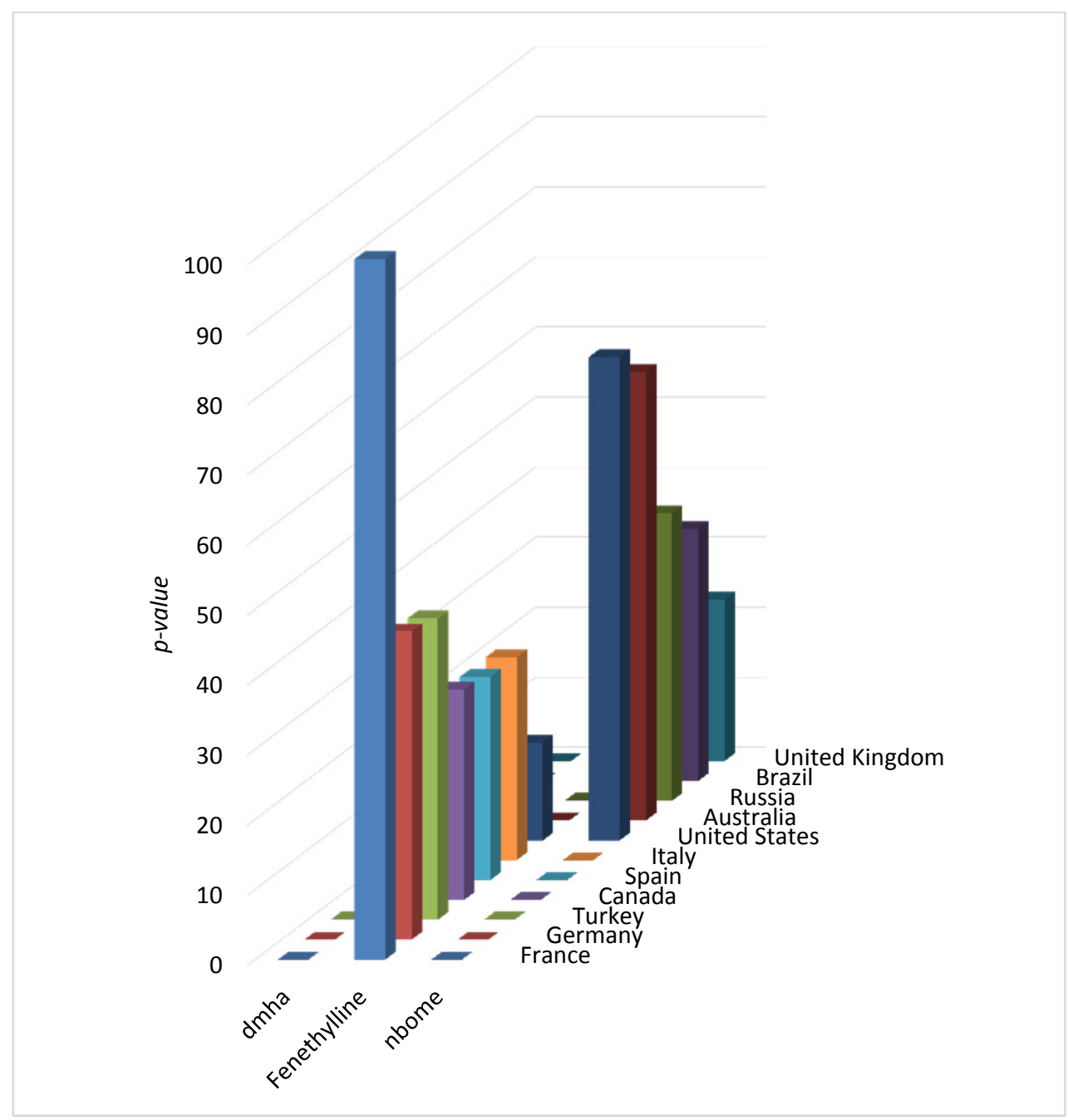

Figure 2. Geo-mapping of dmha, Fenethylline, nbome (keywords) on Google Trends

The top related queries as seen on Google Trends included; captago isis, isis, captagon daesh, captagon efectos, captagon syria, captagon ingredients, droga isis, isis drug, drogue daesh, captagon drog, dmha booster, dmha stimulant, n-bomb drug, 25 b nbome, 25i erowid, nbome droga, 251 nbome, 25 i nbome buy, nbome vs acid, nbome efeitos, nbom, 2cc nbome, 2c-b (Google, 2017). Apparently, all these terms are used by a diverse array of surface web users of different backgrounds, cultures, languages, and countries of origin. Most of these terms were related to either captagon or nbome and to a less extent in connection with octodrine. Octodrine is still ambiguous to the majority of surface web users.

In relation to the diffusion of captaon on the darknet, it was explored via the Grams search engine using two keywords in combination with a boolean operator "captagon OR fenethylline", the snapshot was taken on the $10^{\text {th }}$ of February 2017. Captagon was found to be diffused via e-commerce in five countries (regions); Germany (52\%), European Union (20\%), non-specified worldwide (15\%), Netherlands (10\%), and the UAE (3\%). Captagon e-commerce in the darknet seems to be restricted to the developed western European countries and the developed Arabic countries from the Arabian Gulf region, specifically the United Arab Emirates, Qatar, and Oman.

It was observed that captagon was strictly sold in the form of tablets and in highly variable quantities; captagon 
was only found in three e-markets (AlphaBay, HANSA, and Dream). Only four e-vendors were e-commercing with captagon, and those were nicknamed; GoldenCamel, Infinity-Drugs.to, DoctorMario, and DSQ. The last two nicknames were found to be an alias of the same e-vendor; he (she) is likely to have a European nationality, as he (she) was also involved in the e-commerce of captagon in Netherlands, UAE, and in other non-specified regions within the EU, and worldwide. The basis of power for each e-vendor has been explored. The geo-mapping, e-vendors, and the number of hits are presented (Figure 3).

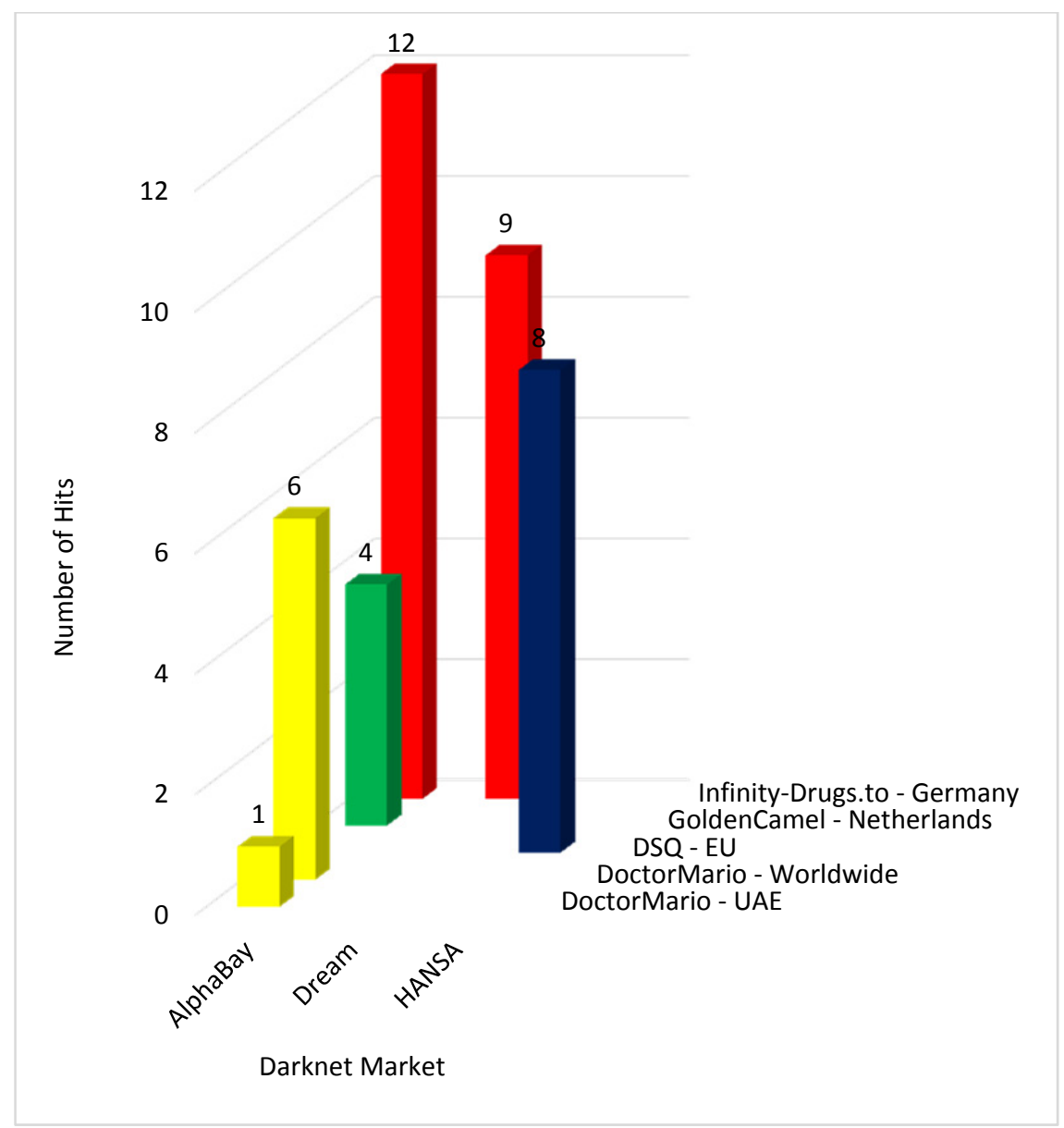

Figure 3. Captagon e-vendors on the Darknet: Location, e-vendors, and the Number of Hits

$\mathrm{NBOMe}(\mathrm{s})$ was found to be more abundant in the e-commerce markets of the darknet; a snapshot was taken on the $10^{\text {th }}$ of February 2017 using the keyword "nbome" OR "NBOME" OR "NBOMe" to explore three renowned e-markets (AlphaBay, HANSA, and Valhalla). The Power scores for e-vendors within each e-market was calculated with high accuracy. On Alphabay, the shipping countries (Figure 4) were; the UK (rank $1^{\text {st }}$ ), US ( $2^{\text {nd }}$ ), Spain, Slovakia, Portugal, Poland, New Zealand, Germany, China, Canada, Belgium, Australia, and Argentina. It seems that e-vendors from the UK and the US are dominating the AlphaBay e-market. However, there were no statistical outliers in connection with the power score of e-vendors; the score was in the range from 167.48 to 393.08; the scoring calculation was based on the e-vendor-related parameters; the number of feedbacks, and the membership duration (e-vendor's antiquity). Three main types (Figure 5) of NBOMe were sold; 25b-, 25c-, and the $25 \mathrm{i}$ - variants. The 25i-NBOMe was the most popular, followed by 25b-NBOMe. Over two dozens of e-vendors were identified (Figure 6); alquimia2017, Baron-JOY, bornagain, Chemical_Express, Dahbome, DailyFix, Electricpower, EuroLivery, Fentastic_UK, FRENCHCONNECTION, GoodzŪK, Keys3r_Soze, littlegoblin, LoveIsTheKey, mr.pills, MrNatural, NBFriend, ososo12345, Psychonauta01, SoulDark, theRoadLessToxic. These nicknames (usernames) can give an insight on the geo-mapping (location), and occasionally the gender of an e-vendor. 


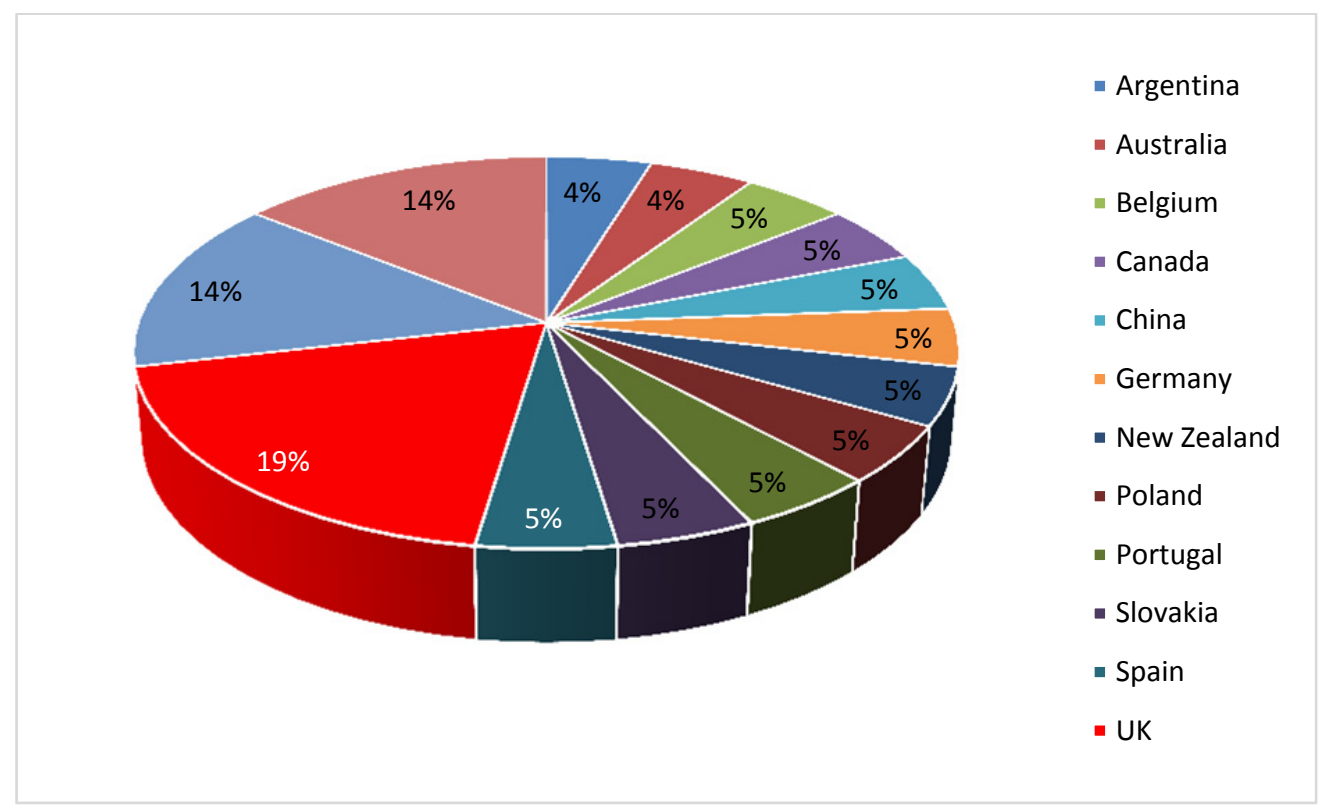

Figure 4. Geo-mapping: Power Score of NBOMe e-vendors on AlphaBay

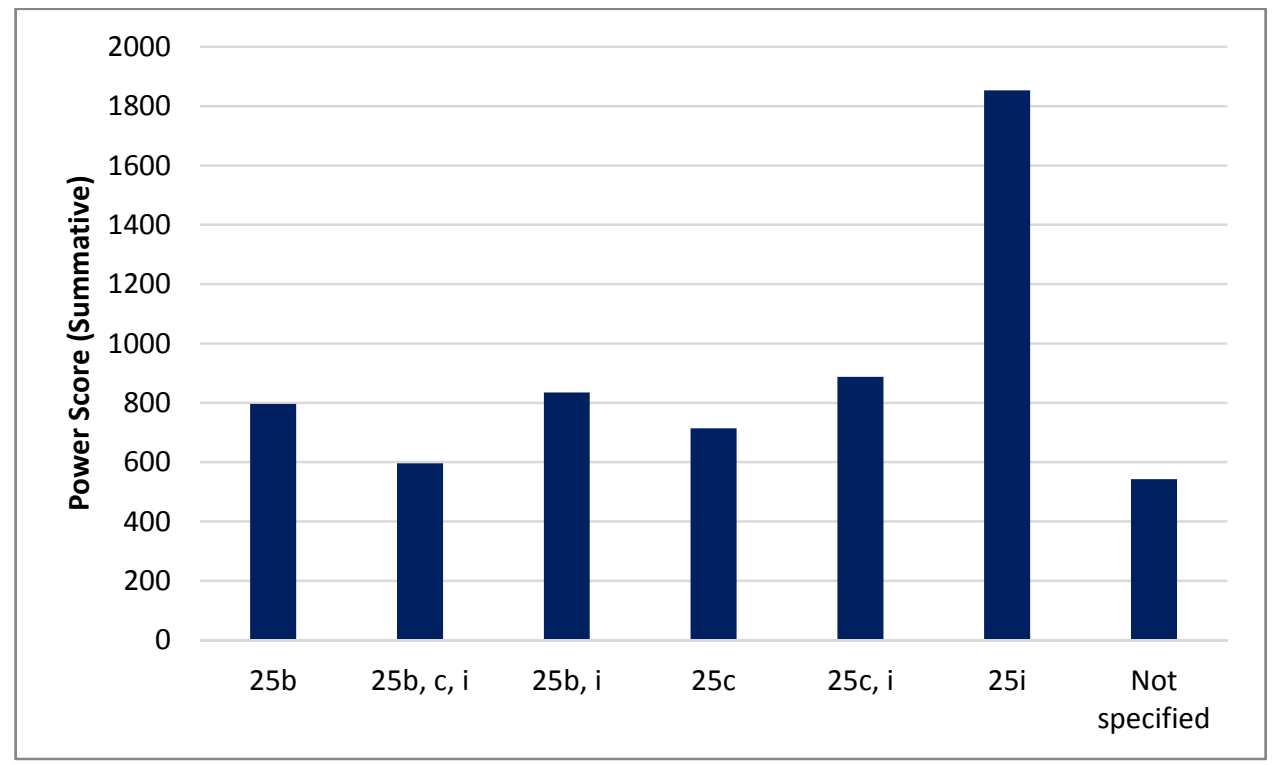

Figure 5. The Main Variants of NBOMe Advertised on AlphaBay 


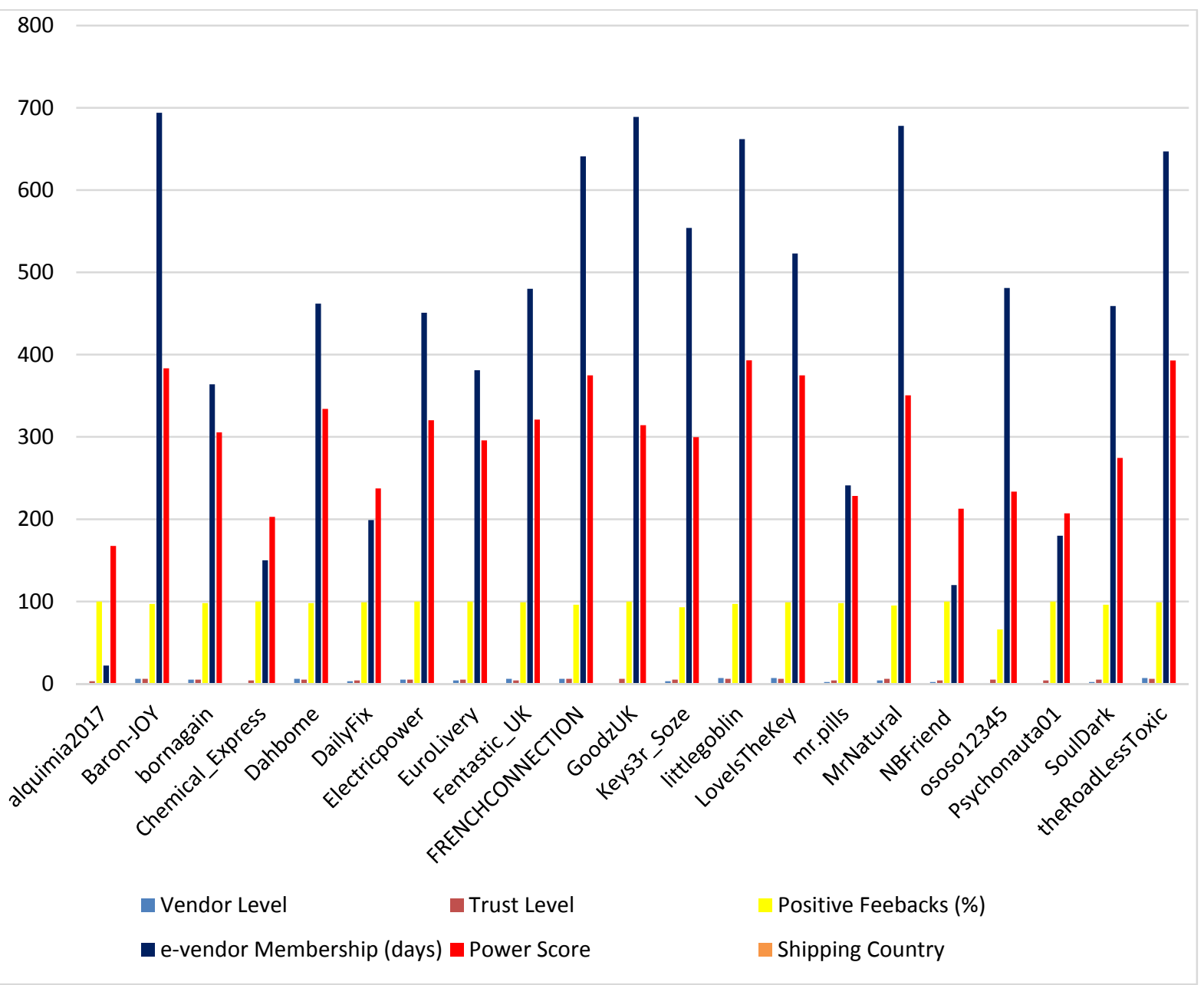

Figure 6. The Characteristics of NBOMe e-vendors' on AlphaBay

The power scores appear to be correlated in a linear fashion with the duration of e-vendor's membership and other parameters related to the specified e-market. Accordingly, a regression model was used to analyse this pattern of correlation. Consequently, it is to be concluded that the power score for each vendor is correlated (positive, linear) to some degree with vendor level, trust level, the number of positive feedbacks, and the membership duration. The strongest correlation was found with e-vendor's trust level $\left(R^{2}\right.$ score $\left.=0.782\right)$, and his (her) membership duration at $\left(\mathrm{R}^{2}=0.798\right)$. A hypothesis was also assumed to test if the e-vendor's power score increases in parallel with the population count of his (her) shipping country (Worldometer, 2017). This hypothesis was rejected after being tested using regression models; it seems that the population count was not correlated with e-vendors' power scoring $\left(\mathrm{R}^{2}=0.003\right)$.

The number of e-vendors within HANSA e-market appeared to be less than in AlphaBay, and nine e-vendors were identified; smart666tiger, GodsGarden, HUEHUEBRASIL, Baron-JOY, mrnatural, mrsunshine, DmanT, ChemicalAllstars, and ElDorado. The $25 \mathrm{i}$ and $25 \mathrm{c}$ were the most advertised variants of NBOMe (Figure 7), these were sold in the US (34\%), Brazil (11\%), Germany (11\%), Slovakia (11\%), Spain (11\%), UK (11\%), US (11\%), and in other unspecified locations (11\%). Power scores were also calculated based on e-vendor's level, the number of positive feedbacks, the number of subscribers, and the membership duration. The power scoring was in the range from 17 to 346; there was one statistical outlier, it belonged to an e-vendor from the US, known by the alias smart666tiger (username). Linear regression was done for power score versus number of subscribers $\left(R^{2}\right.$ score $=0.871)$, membership duration $(0.075)$, vendor level $(0.830)$, the number of positive feedbacks $(0.899)$, population count per shipping country $(0.180)$. The correlation was positive for all with an exception for population count; it appears to be that the e-vendor's power score increases a bit as the population count of his (her) shipping country decreases (negative correlation). 


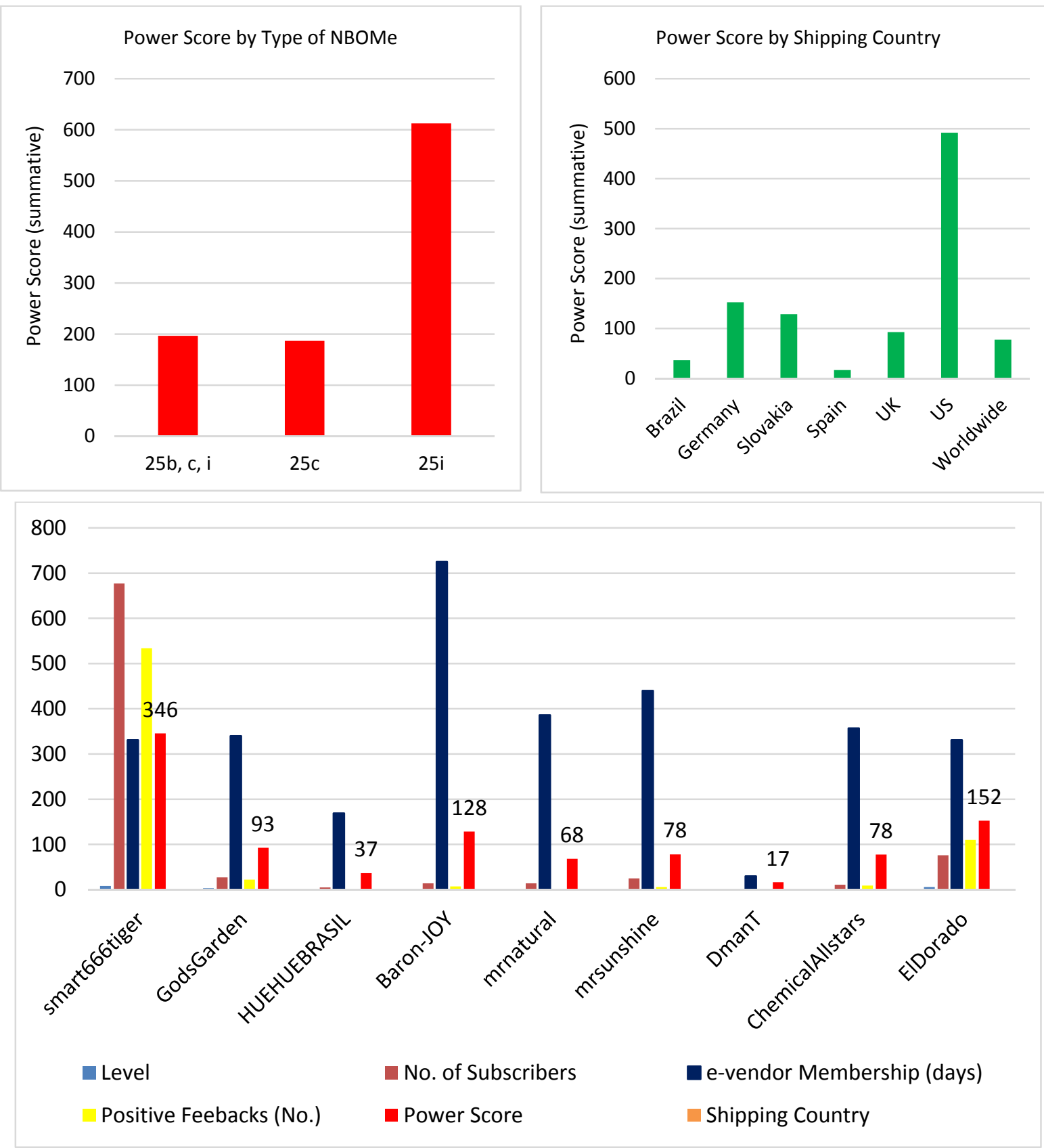

Figure 7. NBOMe on HANSA Market: Variants and Geo-mapping (above), and e-vendors' Power Scoring (below)

Finally, the number of e-vendors in Valhalla e-market was even less $(n=5)$, their usernames; LoveIsTheKey, MrSunshine, domesticdoode1, Citra, and ROCKETCHEM. Similarly, the 25i-NBOMe was the most advertised variant. The main shipping countries were the US, UK, and Spain (Figure 8). Power scores' calculation was based on the number of positive and negative feedbacks (Figure 9); no statistical outliers were detected. The number of e-vendors was not sufficient to infer a substantial regression correlation. However, the raw power score seems to be correlated with population count. There were also alternative shipping countries for e-vendors, at which substances other than NBOMe are traded, and these countries include; France, Belgium, Netherlands, Portugal, Czech Republic, Germany, Australia, Sweden, and China. These locations seem to be concordant with data retrieved from Google Trends. An inter-market inference was made using Student's t-test (independent) in relation to e-vendors power score. There was no significant difference in between AlphaBay versus Valhalla, HANSA versus Valhalla. However, there was a significant difference in the authority scoring of AlphaBay versus HANSA ( $p$-value $<0.001)$. At $90 \% \mathrm{CI}$, there was a significant difference in the power scores of AlphaBay versus Valhalla $(\mathrm{p}=0.092)$. To be concluded, the power scoring of e-vendors from AlphaBay appears to be significantly the highest. 


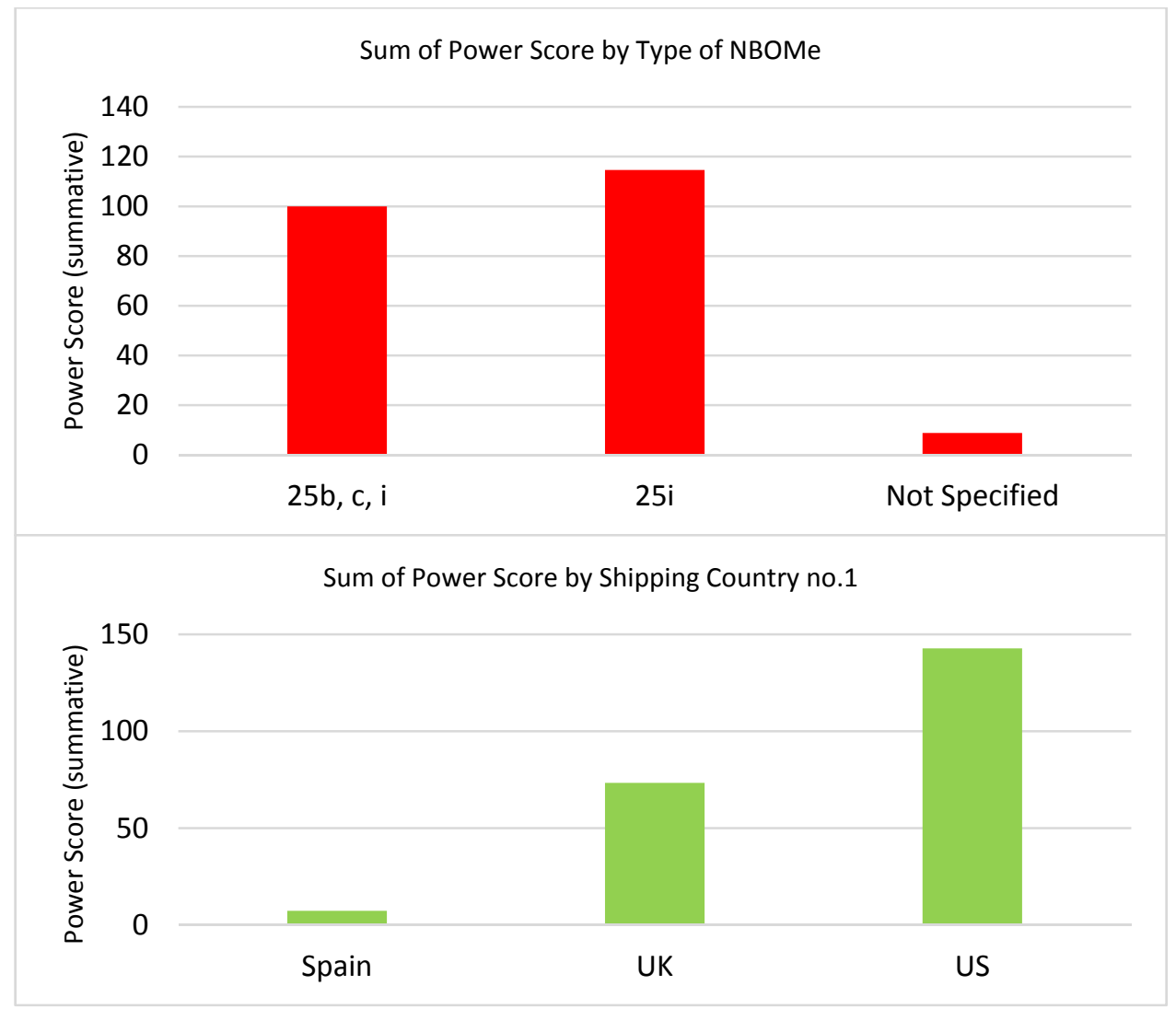

Figure 8. NBOMe on Valhalla Market: Most Popular Variants (above) and Geo-mapping (below)

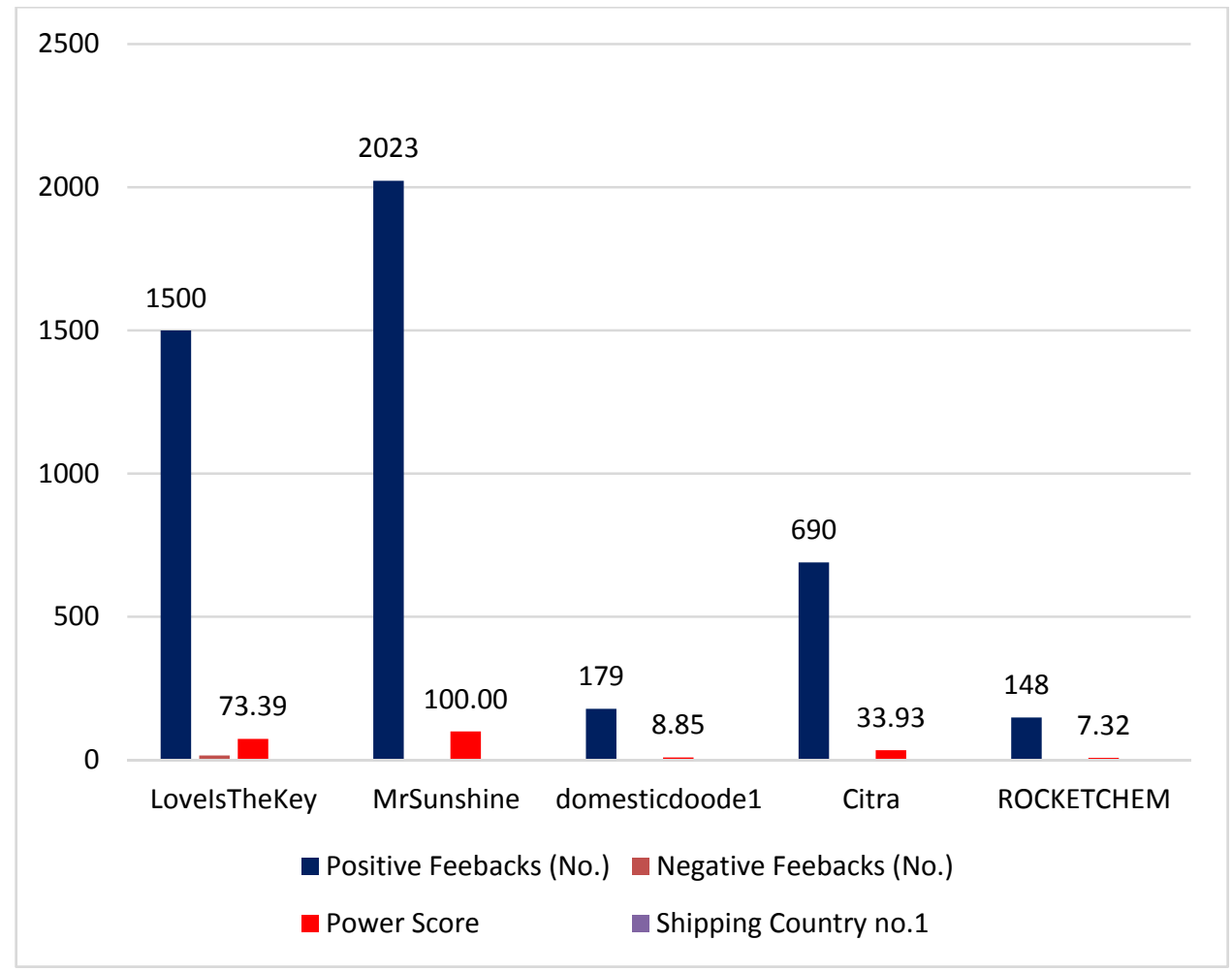

Figure 9. Power Score Characteristics of NBOMe e-vendors on Valhalla 
The power score determinants for the three e-markets are visually presented in a combo graph (Figure 10). Two e-vendors brings particular attention MrNatural, and MrSunshine; each seems to have access to multiple e-markets on the darknet including AlphaBay, Valhalla, HANSA, Oasis, Agora, and Dream. Furthermore, each e-vendor sells similar types of psychoactive substances, traditional and novel, including psychedelics, ecstasy, Stimulants, and Opioids. MrNatural seems to be localised mainly to the US and Romania, while MrSunshine has wider geographic activities in the US, Belgium, Netherlands, Portugal, Czech Republic, and Switzerland. The power score for each e-vendor was calculated based on Grams rating and the number of hits (on Grams search engine). The snapshot was taken on the $11^{\text {th }}$ of February 2017. MrNatural appears to be highly potent on the darknet.

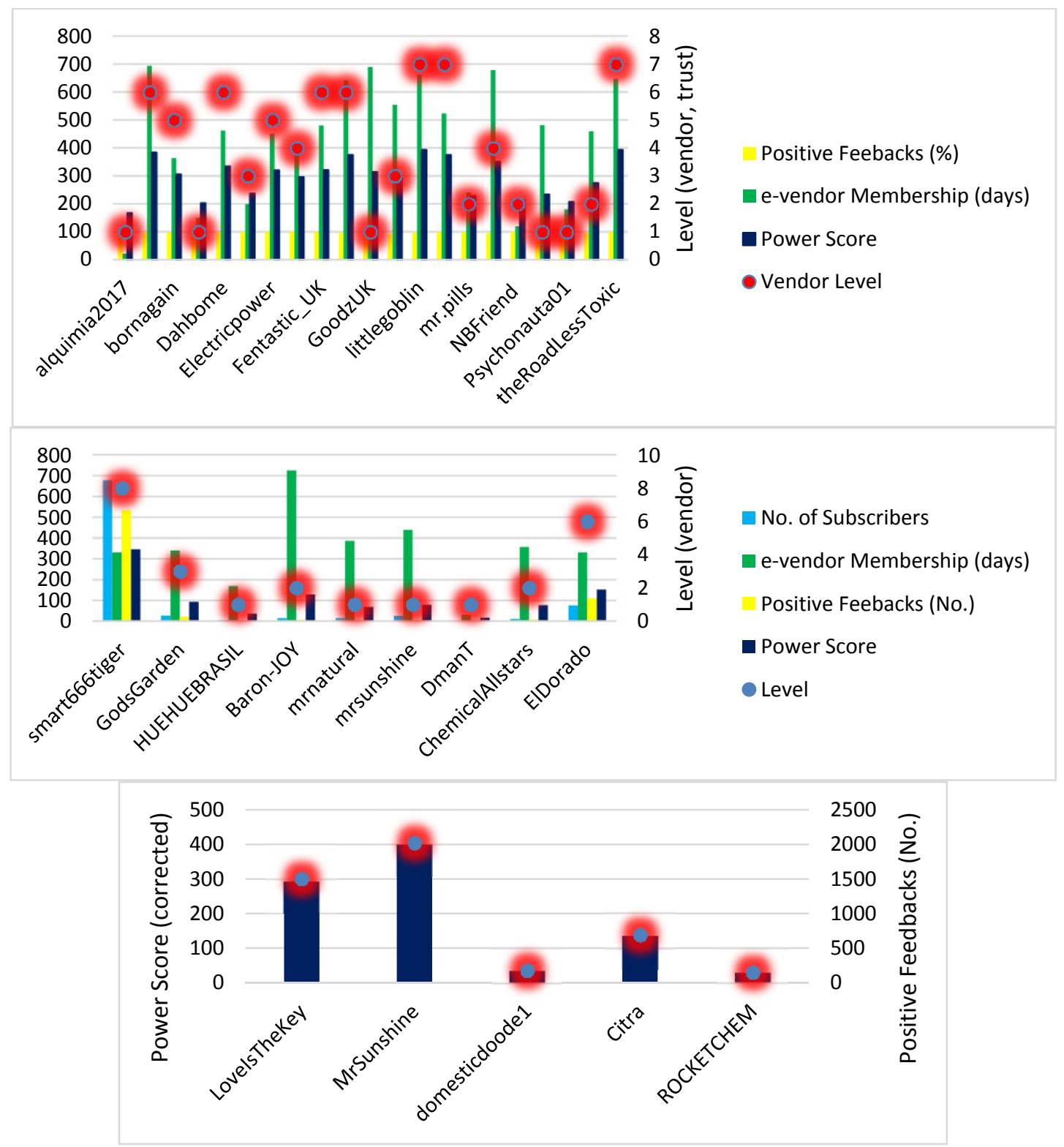

Figure 10. Power Scoring of e-vendors: AlphaBay (above), HANSA (middle), and Valhalla (Below)

\section{Conclusion}

Google Trends analyses confirmed the advanced popularity of captagon over both NBOMe and octodrine; captagon popularity was correlated with terror attacks in the developed world, particularly in western European countries. On the other hand, NBOMe compounds appeared to be popular in Europe, Russia, North American, and Australia. Data from Google Trends can serve as a foundation for data mining techniques for an efficient peremptory warning system against an anticipated attack of terror or a swarm of intoxications and fatalities in 
connection with substance (ab)use. Surface web analyses gave compatible patterns with those observed on the darknet. Both divisions of the internet, surface and deep, were concordant with regards to the geo-mapping of diffusion of these substances with the exception of octodrine.

The Middle East contributed the least to this phenomenon on the darknet; it is very likely that these substances are diffused in Middle Eastern countries by modalities other than the e-commerce. This study proposes a novel method to analyse the e-markets on the darknet via the use of; analysis of the basis of the power of e-vendors, inferential statistics, geo-mapping in parallel with data extracted from Google Trends database, and the implementation of regression models. Furthermore, this integrated analysis eventually brought the attention to exceptional e-vendors of more suspicious activities on the e-marketplace of the darknet.

\section{Competing Interests Statement}

The authors have nothing to be declared.

\section{Source of Funding}

This study has been entirely self-funded.

\section{References}

Al-Imam, A. (2017). Could Hallucinogens Induce Permanent Pupillary Changes in (Ab) users? A Case Report from New Zealand. Case Reports in Neurological Medicine, 2017. https://doi.org/10.1155/2017/2503762

AL-Imam, A., Santacroce, R., Roman - Urrestarazu, A., Chilcott, R., Bersani, G., Martinotti, G., \& Corazza, O. (2017). Captagon: use and trade in the Middle East. Human Psychopharmacology: Clinical and Experimental, $32(3)$.

Al-Imam, A., Simonato, A. P., \& Corazza, O. (2016). Haloperidol, an old antipsychotic with potential use by NPS users in Iraq. Research and Advances in Psychiatry, 3(3), 81-84. Retrieved from https://www.rapjournal.eu/materiale_cic/948_3_3/8031_haloperidol/article.htm

Biddle, P., England, P., Peinado, M., \& Willman, B. (2002, November). The darknet and the future of content protection. In ACM Workshop on Digital Rights Management (pp. 155-176). Springer, Berlin, Heidelberg.

Buxton, J., \& Bingham, T. (2015). The rise and challenge of dark net drug markets. Policy Brief, 7.

Celestini, A., Me, G., \& Mignone, M. (2017, January). Tor Marketplaces Exploratory Data Analysis: The Drugs Case. In International Conference on Global Security, Safety, and Sustainability (pp. 218-229). Springer, Cham.

Chung, H., Lee, J., \& Kim, E. (2016). Trends of novel psychoactive substances (NPSs) and their fatal cases. Forensic Toxicology, 34(1), 1-11. https://doi.org/10.1007/s11419-015-0286-5

Dos Santos, R. G., Osório, F. L., Crippa, J. A. S., \& Hallak, J. E. (2016). Classical hallucinogens and neuroimaging: A systematic review of human studies: Hallucinogens and neuroimaging. Neuroscience \& Biobehavioral Reviews, 71, 715-728. https://doi.org/10.1016/j.neubiorev.2016.10.026

Fayyad, U., Piatetsky-Shapiro, G., \& Smyth, P. (1996). From data mining to knowledge discovery in databases. $A I$ magazine, 17(3), 37.

Fellows, E. J. (1947). The pharmacology of 2-amino-6-methylheptane. Journal of Pharmacology and Experimental Therapeutics, 90(4), 351-358.

Google. Google Trends. Retrieved $25 \quad$ February, 2017, from https://trends.google.com/trends/explore?date=2012-01-01\%202017-01-01\&q=dmha,\%2Fm\%2F0dxk1p,nb ome (accessed).

Google. Google Trends. $\quad$ Retrieved $25 \quad$ February, 2017, from https://trends.google.com/trends/explore?date=2012-01-01\%202017-01-01\&q=octodrine,captagon,n-bomb (accessed 25 February 2017).

Han, J., Pei, J., \& Kamber, M. (2011). Data mining: concepts and techniques. Elsevier.

Kohavi, R., \& Provost, F. (2001). Applications of data mining to electronic commerce. Data mining and knowledge discovery, 5(1/2), 5-10. https://doi.org/10.1023/A:1009840925866

Krabseth, H. M., Tuv, S. S., Strand, M. C., Karinen, R. A., Wiik, E., Vevelstad, M. S., ... \& Vindenes, V. (2016). Novel psychoactive substances. Tidsskrift for den Norske laegeforening: tidsskrift for praktisk medicin, ny raekke, 136(8), 714-717. https://doi.org/10.4045/tidsskr.15.1278 
Kravitz, M., \& Nichols, W. (2016). A Bitter Pill to Swallow: Connections between Captagon, Syria, and the Gulf. Journal of International Affairs, 69(2), 31.

Kyriakou, C., Marinelli, E., Frati, P., Santurro, A., Afxentiou, M., Zaami, S., \& Busardo, F. P. (2015). NBOMe: new potent hallucinogens-pharmacology, analytical methods, toxicities, fatalities: a review. European review for medical and pharmacological sciences, 19(17), 3270-3281.

Ling, W. A. L. T. E. R., Mooney, L. A. R. I. S. S. A., \& Rawson, R. A. (2013). Amphetamine-type stimulants. Addictions: a comprehensive guidebook.

Mayer, F. P., Luf, A., Nagy, C., Holy, M., Schmid, R., Freissmuth, M., \& Sitte, H. H. (2017). Application of a Combined Approach to Identify New Psychoactive Street Drugs and Decipher Their Mechanisms at Monoamine Transporters. Neuropharmacology of New Psychoactive Substances (NPS) The Science Behind the Headlines, 333-350.

Mulazzani, M., Reschl, P., Huber, M., Leithner, M., Schrittwieser, S., Weippl, E., \& Wien, F. C. (2013, May). Fast and reliable browser identification with javascript engine fingerprinting. In Web 2.0 Workshop on Security and Privacy (W2SP) (Vol. 5).

Nichols, D. E. (2016). Psychedelics. Pharmacological reviews, 68(2), 264-355. https://doi.org/10.1124/pr.115.011478

Orsolini, L., Papanti, D., Vecchiotti, R., Valchera, A., Corkery, J., \& Schifano, F. (2016). Novel psychoactive substances. European Psychiatry, 33, S59-S60. https://doi.org/10.1016/j.eurpsy.2016.01.945

Rao, R. B., \& Hoffman, R. S. (2014). Cocaine and other sympathomimetics. Rosen's Emergency Medicine: Concepts and Clinical Practice (8th ed.). Philadelphia, PA: Elsevier Saunders.

Shanks, K. G., Sozio, T., \& Behonick, G. S. (2015). Fatal intoxications with 25B-NBOMe and 25I-NBOMe in Indiana during 2014. Journal of analytical toxicology, 39(8), 602-606. https://doi.org/10.1093/jat/bkv058

Simmler, L. D., Rickli, A., Hoener, M. C., \& Liechti, M. E. (2014). Monoamine transporter and receptor interaction profiles of a new series of designer cathinones. Neuropharmacology, 79, 152-160. https://doi.org/10.1016/j.neuropharm.2013.11.008

Worldometer. Population. Retrieved 25 February, 2017, from http://www.worldometers.info/population/

\section{Copyrights}

Copyright for this article is retained by the author(s), with first publication rights granted to the journal.

This is an open-access article distributed under the terms and conditions of the Creative Commons Attribution license (http://creativecommons.org/licenses/by/4.0/). 